\title{
Clinical Social Work and Evidence-Based Practice: An Introduction to the Special Issue
}

\author{
Bruce A. Thyer $\cdot$ Monica Pignotti
}

Published online: 17 August 2011

(C) Springer Science+Business Media, LLC 2011

We are very pleased to have been asked to coordinate this special issue of the Clinical Social Work Journal, oriented around the general topic of evidence-based practice (EBP). EBP has aroused considerable interest, optimism, and some controversy within our field since it was first introduced into social work by Gambrill (1999). A PsycINFO search we completed in June 2011, using "social work" AND "evidence-based practice", appearing in abstracts published during the past 5 years (2006-2010), found twice as many citations than a similar search using "social work" AND "psychotherapy" as key words. This suggests the remarkable influence the EBP process has exerted within our disciplinary literature in recent years. Working closely with this journal's Editor, Dr. Carol Tosone, we were able to solicit the collection of papers you now find within these pages, some from proponents of EBP and others from individuals more cautious about this relatively new approach. We are grateful to these authors for providing their contributions to this topic and to Dr. Tosone for supporting this project.

The impetus for our undertaking this special issue was the publication of Leichsenring and Rabung's (2008) metaanalysis of the effectiveness of long term psychodynamic psychotherapy (LTPP) in the prestigious journal JAMA (formerly known as the Journal of the American Medical Association). These authors examined 23 different psychotherapy outcome studies that involved the provision of psychodynamic psychotherapy for at least 1 year, in the

\footnotetext{
B. A. Thyer $(\bowtie) \cdot$ M. Pignotti

College of Social Work, Florida State University,

296 Champions Way, Tallahassee, FL 32306, USA

e-mail: Bthyer@fsu.edu

M. Pignotti

e-mail: Pignotti@att.net
}

context of a published quasi-experimental or randomized clinical trial. These studies included a total over 1,000 patients who received LTPP, and the major finding was said that LTPP was significantly superior to shorter-term methods of psychotherapy. Subsequent reader responses in Letters to the Editor published in JAMA and a critical analysis (Bhar et al. 2010) indicate that this article generated considerable controversy and some of its findings were called into question. In some ways however, the accuracy of Leichsenring and Rabung's (2008) conclusions are not as significant as is the very fact that LTPP proved to be amenable to meta-analysis, however imperfect. Coupled with the publication of a related randomized controlled trial on psychoanalytic psychotherapy for panic disorder (Milrod et al. 2007) and a systematic review on the effectiveness of long-term psychoanalytic therapy (De Maat et al. 2009), such studies put to rest the oft-heard contention that the methodological tools of outcome studies and clinical trials are inherently deficient tools to dissect and isolate the presumptively subtle effects of relationship-oriented psychotherapies (e.g., Thorpe and Baker 1959; Pharis 1976; Richardson 2001). Such outcome studies can be done well and there is a rather substantial literature in this area, studies of gradually increasing rigor and methodological sophistication. Clearly, psychodynamic psychotherapy is amenable to credible scientific appraisal, in terms of its effects, and ultimately, mechanisms of action. Any therapy that is contended to help improve client well-being is fair game for scientific investigation, to the extent it makes testable claims relating to outcomes and enhanced functioning. Of course findings obtained under carefully controlled trial conditions need to replicated under clinically representative circumstances, with heterogeneous clients and clinicians of diverse backgrounds, and steps are also being undertaken in this direction, by social workers (e.g., Roseborough 2006; 
Roseborough et al. in press), as well as by researchers in other disciplines (e.g., Shadish et al. 2000).

We thought it would be useful to bring the Leichsenring and Rabung (2008) study to the attention of the readership of the Clinical Social Work Journal, along with some critical appraisals by clinically experienced social work researchers. By illustrating how LTPP is being evaluated by contemporary researchers, and yielding an array of preexperimental, quasi-experimental, and experimental studies, and subsequent meta-analyses and systematic reviews (see Cochrane.org for dozens of systematic reviews on the effects of psychotherapy), these and related approaches to insight and behavior change have become full participants in the evidence-based practice movement. We solicited an array of submissions on topics closely related to EBP, and we were very fortunate to obtain a diverse set of contributions. All received extensive peer review prior to their acceptance, in keeping the the journal's usual process for selected articles for publication. First we have commentaries from four sets of authors who analyzed and critiqued Leichsenring and Rabung's (2008) meta-analysis. This is followed by four descriptive and methodological articles dealing with topics important to EBP - the role of systematic reviews and the work of the Campbell Collaboration in clinical social work; an overview of the importance of sampling methods in the design and conduct of outcome studies; how to efficiently search electronic data-bases for primary studies, meta-analyses, and systematic reviews, and an judicious overview of the strengths and limitations of EBP. We included a very interesting descriptive report of the efforts of the New York Office of Mental Health's efforts to encourage practitioners to adopt empiricallysupported treatments, which is not the same thing as the process of EBP, as we note in our own provocatively titled paper "Evidence-based Practices Do Not Exist". Lastly we have a comprehensive review article prepared by leading social work clinical researchers on the topic of effectively treating clients who compulsively hoard objects, a topic increasingly recognized as a common problem which can lead to considerable social dysfunction, and one which even has a television show devoted to it (http://www.aetv. com/hoarders/). Reviews such as this can be of immense value to social workers seeking an accurate and comprehensive summary of what is known relating to the treatment of clients with specific problems. Obviously, as independent editors, we do not agree with everything stated in the articles comprising this special issue. But in the interests of encouraging a diversity of opinions we blindly reviewed each of these papers, with the able assistance of other reviewers, and recommended their acceptance as useful contributions to this discourse.

One point we believe is worth clarifying is how to evaluate the comparativeness effectiveness of two or more different psychotherapies. One approach is to conduct a meta-analysis of one therapy (call it X-therapy) compared to no-treatment or to credible placebo, and calculate an effect size. Then to compare this effect size with that of similar but separately conducted meta-analyses on the effectiveness of another psychotherapy ( $Y$ therapy). If the effect size for $\mathrm{X}$ is equal to that obtained for $\mathrm{Y}$, then some writers contend that $\mathrm{X}$ and $\mathrm{Y}$ therapies yield equivalent results, and if $\mathrm{X}$ has a larger effect size than $\mathrm{Y}$, then is concluded to be superior to Y. This was the logic behind the review of psychodynamic psychotherapy (PP) outcome studies completed by Shedler (2010) in which he concluded that PP is as effective as cognitive behavior therapy (CBT). We believe that this approach to appraising comparative effectiveness is incorrect, given the great differences that occur within and across psychotherapy studies. Instead, the more credible way to evaluate the relative effectiveness of $\mathrm{X}$ versus $\mathrm{Y}$ is to limit one's meta-analysis to only include studies that directly examined $\mathrm{X}$ versus $\mathrm{Y}$ in a head-to-head comparison, studies that randomly assigned clients to X-therapy, and Y-therapy, and to either a waiting-list control condition or to a placebo-treatment group. This is of course a more conservative method of analysis, but justifiable given the importance of the issues under investigation. It controls for, in part, the problem encountered when the methodological rigor of studies evaluating $\mathrm{X}$ or $\mathrm{Y}$ therapies are not approximately equivalent. If one therapy enjoys a far greater number of outcome studies than the other, one can compare the effect sizes for the two therapies, but similarity in effect sizes alone does not equate to equivalence in evidentiary support of clinical effectiveness.

These are exciting times for clinical social workers. Research support for the services members of our discipline provide is substantially growing. The systematic methods of science embraced by EBP, while imperfect, present the profession with the best available tools to empirically ascertain the short and long term effects of specific psychotherapies, their side effects, long term results, and comparative effectiveness. As Francis Bacon observed, "Truth arises more readily from error than from confusion". The errors which can arise through scientific investigations usually possess the virtues of being transparent and eventually correctable. This is an advantage of science over other ways of knowing.

\section{References}

Bhar, S. S., Thombs, B. D., Pignotti, M., Bassel, M., Jewett, L., Coyne, J. C., et al. (2010). Is longer term psychodynamic psychotherapy more effective than shorter term therapies: Review and critique of the evidence. Psychotherapy and Psychosomatics, 79, 208-216. 
De Maat, S., de Jonghe, F., Schoevers, R., \& Dekker, J. (2009). The effectiveness of long-term psychoanalytic therapy: A systematic review of empirical studies. Harvard Review of Psychiatry, 17(1), 1-23.

Gambrill, E. (1999). Evidence-based practice: An alternative to authority-based practice. Families in Society, 80, 341-350.

Leichsenring, F., \& Rabung, S. (2008). Effectiveness of long-term psychotherapy: A meta-analysis. The Journal of the American Medical Association, 300, 1551-1565.

Milrod, B., Leon, A. C., Busch, F., Rudden, M., Schwalberg, M., Clarkin, J., et al. (2007). A randomized controlled trial of psychoanalytic psychotherapy for Panic Disorder. American Journal of Psychiatry, 164, 265-272.

Pharis, M. (1976). Ten reasons why I am not bothered by outcome studies which claim psychotherapy is ineffective. Clinical Social Work Journal, 4, 58-61.

Richardson, P. (2001). Evidence-based practice and the psychodynamic psychotherapies. In C. Mace, S. Moorey, \& B. Roberts (Eds.), Evidence in the psychological therapies: A critical guide for practitioners (pp. 157-173). Philadelphia, PA: BrunnerRoutledge.

Roseborough, D. (2006). Psychodynamic psychotherapy: An effectiveness study. Research on Social Work Practice, 16, 166-175.

Roseborough, D., McLeod, J. T., \& Bradshaw, W. H. (in press). Psychodynamic psychotherapy: A quantitative, longitudinal perspective. Research on Social Work Practice. doi:10.1177/ 1049731511412790.
Shadish, W. R., Matt, G., Navarro, A., \& Phillips, G. (2000). The effects of psychological therapies under clinically representative conditions: A meta-analysis. Psychological Bulletin, 126, $512-529$.

Shedler, J. (2010). The efficacy of psychodynamic psychotherapy. American Psychologist, 65, 98-109.

Thorpe, J. G., \& Baker, A. A. (1959). Statistics, science, and psychiatry. Archives of General Psychiatry, 1, 338-341.

\section{Author Biographies}

Bruce A. Thyer, Ph.D is professor and former Dean with the College of Social Work at Florida State University. Dr. Thyer earned his $\mathrm{Ph} . \mathrm{D}$. in social work and psychology from the University of Michigan in 1982. He is an LCSW and edits the journal Research on Social Work Practice.

Monica Pignotti received her MSW from Fordham University in 1996 and her Ph.D. in social work from Florida State University in 2009. She is a LMSW and is the co-author, with Bruce Thyer, of Science and Pseudoscience in Social Work (Oxford University Press, 2012). 